Jenuth JP, Peterson AC, Fu K, Shoubridge EA (1996) Random genetic drift in the female germline explains the rapid segregation of mammalian mitochondrial DNA. Nat Genet 14: 146-151

Johns DR (1996) The other human genome: mitochondrial DNA and disease. Nat Med 2:1065-1068

Lander ES, Schork NJ (1994) Genetic dissection of complex traits. Science 265:2037-2048

Luft R (1994) The development of mitochondrial medicine. Proc Natl Acad Sci USA 91:8731-8738

SAS Institute (1987) SAS/STAT guide for personal computers, version 6 ed. SAS Institute, Cary, NC

Shigenaga MK, Hagen TM, Ames BN (1994) Oxidative damage and mitochondrial decay in aging. Proc Natl Acad Sci USA 91:10771-10778

Suomalainen A, Kaukonen J, Amati P, Timonen R, Haltia M, Weissenbach J, Zeviani M, et al (1995) An autosomal locus predisposing to deletions of mitochondrial DNA. Nat Genet 9:146-151

Torroni A, Schurr TG, Cabell MF, Brown MD, Neel JV, Larsen M, Smith DG, et al (1993) Asian affinities and continental radiation of the four founding Native American mtDNAs. Am J Hum Genet 53:563-590

Wallace DC (1994) Mitochondrial DNA sequence variation in human evolution and disease. Proc Natl Acad Sci USA 91:8739-8746

World Health Organization (WHO) (1985) Diabetes mellitus: report of a WHO study group. Tech rep 727, WHO, Geneva

Address for correspondence and reprints: Dr. Robert A. Hegele, DNA Research Laboratory, St. Michael's Hospital, 30 Bond Street, Toronto, Ontario, M5B 1W8, Canada. E-mail: robert.hegele@utoronto.ca

(C) 1997 by The American Society of Human Genetics. All rights reserved. 0002-9297/97/6006-0038\$02.00

Am. J. Hum. Genet. 60:1555-1558, 1997

\section{Up-Regulation of the Brain and Purkinje-Cell Forms of Dystrophin Transcripts, in Becker Muscular Dystrophy}

To the Editor:

Duchenne muscular dystrophy (DMD) and Becker muscular dystrophy (BMD) are allelic disorders caused by mutations in the DMD gene. Clinical pictures in BMD patients are more heterogeneous than those in DMD patients; some patients with BMD exhibit dilated cardiomyopathy in the absence of overt skeletal muscle atrophy or weakness. We previously reported two atypical BMD patients from two unrelated families, who showed severe dilated cardiomyopathy in their teens without obvious skeletal muscle atrophy or weakness (Yoshida et al. 1993). Both patients showed slight calf pseudohypertrophy, and one of them had exertional myalgia. Molecular genetic analysis revealed a deletion ranging from the first muscle exon to the first muscle intron, in the DMD gene in these patients (Yoshida et al. 1993).

Meanwhile, the term " $\mathrm{X}$-linked dilated cardiomyopathy" ("XLDCM," "XLCM," or "XLDC"), originally proposed by Berko and Swift (1987), now is assigned to a clinical phenotype of dystrophinopathy that is characterized by severe dilated cardiomyopathy without apparent skeletal myopathy (Muntoni et al. 1993; Towbin et al. 1993). To date, five mutations in the DMD gene have been reported in this phenotype (Muntoni et al. 1993; Oldfors et al. 1994; Towbin et al. 1994; Franz et al. 1995; Milasin et al. 1996), and a correlation between the XLDCM phenotype and the locations of mutations in the DMD gene has been controversial. Among these mutations, two were identified at the $5^{\prime}$ end of the DMD gene; one mutation was a deletion that removed the muscle promoter, the first muscle exon, and part of the first muscle intron (Muntoni et al. 1993), and the other was a point mutation in the $5^{\prime}$ splice site of the first muscle intron (Milasin et al. 1996). Together with our report (Yoshida et al. 1993), these data indicate that the mutations at the $5^{\prime}$ end of the DMD gene are associated with a distinct phenotype of dystrophinopathy with preferential involvement of cardiac muscle. Further examinations in XLDCM patients revealed that the expression of the brain and Purkinje-cell forms of dystrophin transcripts was up-regulated in the skeletal muscle, whereas there was a lack of the muscle form of dystrophin transcripts (Muntoni et al. 1995; Milasin et al. 1996), suggesting that compensatory transcripts from the brain and Purkinje-cell promoters may maintain adequate levels of dystrophin in the skeletal muscle of XLDCM patients (Muntoni et al. 1995; Milasin et al. 1996). We also analyzed the expression of each form of dystrophin transcripts in one atypical BMD patient (patient 1 ) with a deletion affecting the first muscle exon and the first muscle intron, in the DMD gene, and also in two BMD patients, with typical skeletal muscle involvement, having a deletion of either exons 45-47 (patient 2) or exons 45-48 (patient 3).

Patient 1, a 24-year-old man, showed slight calf pseudohypertrophy and exertional cramping myalgia in the legs but not muscle atrophy or weakness. He was free of cardiac symptoms; however, an electrocardiogram (ECG) showed an increased $R / S$ ratio in leads $V_{1}$ and $\mathrm{V}_{2}$ and prominent $\mathrm{Q}$ waves in leads II, III, and $\mathrm{a} \mathrm{V}_{\mathrm{F}}$. An echocardiogram (UCG) revealed diffuse hypokinesis of the left ventricle (LV), with dilatation (LV end-diastolic dimension [LVDd] of $64 \mathrm{~mm}, \mathrm{LV}$ end-systolic dimension [LVDs] of $52 \mathrm{~mm}$, and fractional shortening [FS] of $19 \%$ ). Especially the posterior wall of the LV was markedly thin and akinetic. The LV ejection fraction (EF; normal $>60 \%$ ) was depressed severely $(26 \%)$. Mild mitral valve regurgitation also was observed. A ${ }^{201} \mathrm{Tl}$ 

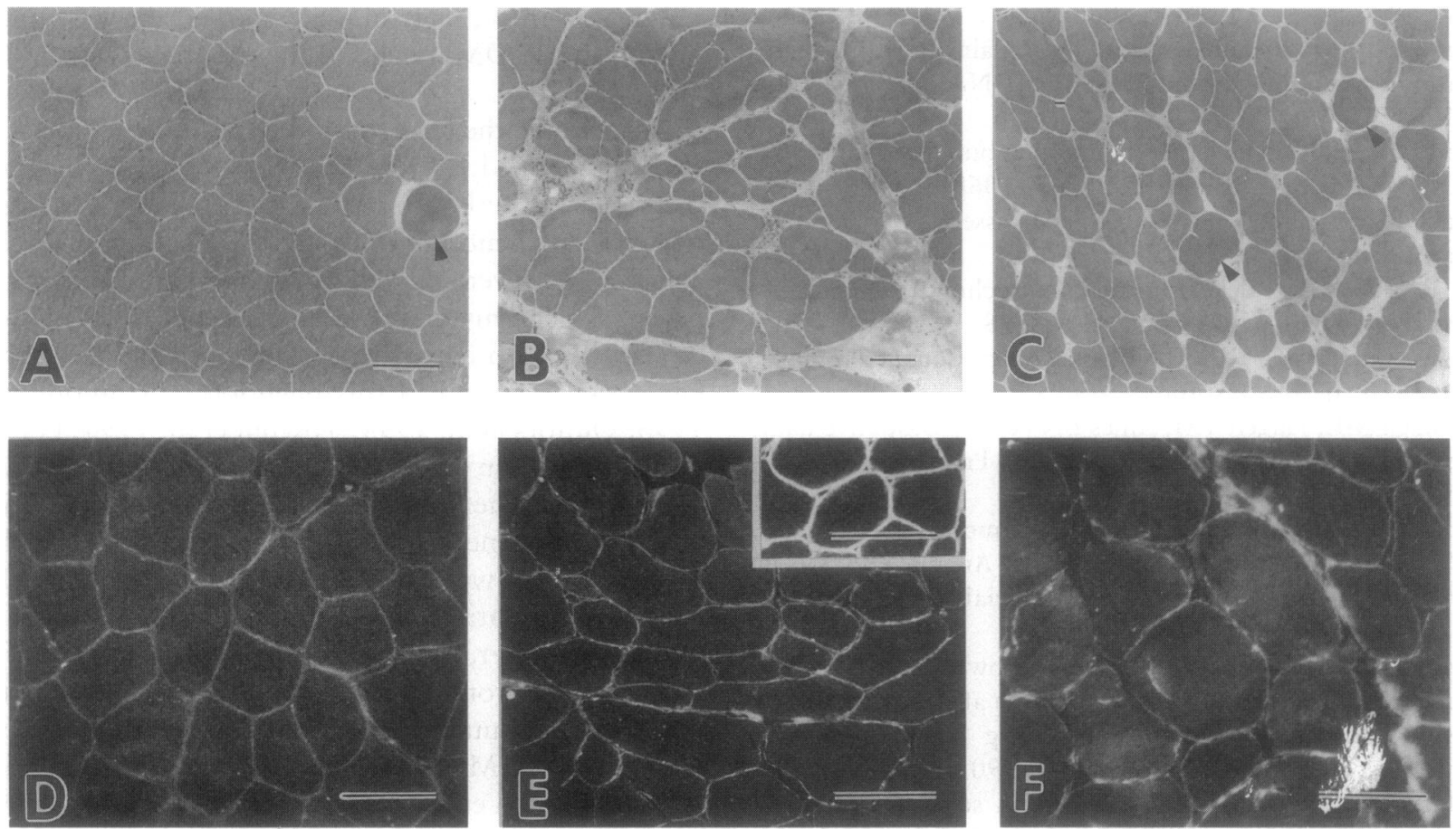

Figure 1 Muscle-biopsy findings. All samples were obtained from the left-biceps brachii of the patients. $A$ and $D$, Patient $1 . B$ and $E$, Patient 2 (E [inset], control). $C$ and $F$, Patient 3. Panels $A, B$, and $C$ show frozen sections stained with hematoxylin-eosin. Panels $D, E$, and $F$ show frozen sections stained with the antibody (dys 2) against the C-terminal domain of dystrophin. In patient 1 (D), all muscle fibers showed continuous dystrophin immunostaining, but the intensity of fluorescence was paler than that in the control ( $E$ [inset]). Arrowheads indicate opaque fibers. The bars indicate $100 \mu \mathrm{m}$.

scintigram showed a decrease in uptake on the posterolateral wall of the LV. His younger brother died at the age of 18 years, because of congestive heart failure (Yoshida et al. 1993). Multiplex PCR and Southern blot analysis confirmed a unique deletion affecting part of the first muscle exon and intron in these siblings (Yoshida et al. 1993). This deletion affected the initiation codon ATG in the first muscle exon but not the muscle promoter and the transcription start site. The genomic regions for the brain and Purkinje-cell promoters were unaffected. The second exon also was intact. Heniatoxylin-eosin staining of the skeletal muscle of patient 1 showed that there was mild variation in fiber size, with a slight increase in the number of internal nuclei and the presence of scattered opaque fibers, although there were no necrotic fibers and no increase of interstitial connective tissue (fig. 1A). Immunofluorescence staining using antibodies against the $\mathrm{N}$-terminal (dys 3 antibody), rod (dys 1 antibody), and C-terminal (dys 2 antibody) domains (Novocastra Laboratories) showed that all fibers appeared to be labeled continuously but that the intensity of fluorescence was weaker than that in control skeletal muscle (fig. $1 D$ and $E$ [inset]). In western blot analysis using the dys 2 antibody, reduced amounts of dystrophin were detected, but the size of the dystrophin was normal ( $\sim 400 \mathrm{kDa}$; data not shown).
Patient 2 was a 56-year-old man with atrophy and weakness of proximal limb muscles, which started during his childhood. Since the age of 50 years, he occasionally has experienced chest discomfort and nocturnal dyspnea. Cardiomegaly was noted on a chest roentgenogram (cardiothoracic ratio of $55 \%$ ). ECG showed a prominent $\mathrm{Q}$ wave in lead $\mathrm{a} \mathrm{V}_{\mathrm{L}}, \mathrm{ST}$ depression in leads $\mathrm{V}_{1}-\mathrm{V}_{4}$, and negative $\mathrm{T}$ waves in leads $\mathrm{V}_{5}$ and $\mathrm{V}_{6}$. UCG revealed LV hypokinesis with dilatation (LVDd of 59 $\mathrm{mm}$, LVDs of $50 \mathrm{~mm}$, and FS of $15 \%$ ), decreased EF of $30 \%$, and mild mitral valve regurgitation. Severe reduction of the ${ }^{201} \mathrm{Tl}$ uptake was observed on the posteroinferior wall and the apex of the LV. The muscle biopsy revealed marked variation in fiber size, with round atrophic fibers, an increased number of internal nuclei, and proliferation of connective tissue (fig. $1 B$ ). The diagnosis of BMD was confirmed by patchy and discontinuous immunostaining of dystrophin in the biopsied muscle (fig. $1 E$ ) and by a deletion affecting exons $45-47$ in the DMD gene.

Patient 3 was a 30 -year-old man with muscle atrophy and weakness in both thighs and with calf pseudohypertrophy. He had right ankle joint contracture at birth and could not walk until the age of 3 years. Since the age of 29 years, he has not been able to walk up stairs: A physical examination at the age of 30 years showed that 
he had no cardiac symptoms or signs. ECG showed an increased $R / S$ ratio in lead $V_{1}$ and abnormal $Q$ waves in leads $\mathrm{I}, \mathrm{a} \mathrm{V}_{\mathrm{L}}$, and $\mathrm{aV} \mathrm{F}_{\mathrm{F}} . \mathrm{LV}$ hypokinesis (LVDd of 52 $\mathrm{mm}$, LVDs of $38 \mathrm{~mm}$, and FS of 27\%) and a slightly decreased EF of $52 \%$ were detected by UCG. A ${ }^{201} \mathrm{Tl}$ scintigram revealed a mild reduction of uptake on the posteroinferior and lateral walls of the LV. The histological findings and the dystrophin immunostaining pattern, of the skeletal muscles, were similar to those seen in patient 2 (fig. $1 C$ and F). Patient 3 had a deletion affecting exons $45-48$ in the DMD gene.

We extracted total RNA from skeletal muscle specimens from BMD patients and from a control patient with dermatomyositis, using RNAzol (Tel-Test) in accordance with the manufacturer's specifications. Reverse-transcription-PCR (RT-PCR) was performed with the Stratascript ${ }^{\mathrm{TM}}$ RT-PCR kit. The forward oligonucleotide primer (M1) used for amplification of the muscle form of dystrophin transcripts was the same in sequence as that of primer $1 \mathrm{~F}$, which was described in the study by Sakuraba et al. (1991). Forward primers for the brain (B1) and Purkinje-cell (P1) forms of dystrophin transcripts and the reverse primer (M4) located in exon 4 of the DMD gene were synthesized as described in the study by Muntoni et al. (1995). PCR was performed in a reaction volume of $50 \mu \mathrm{l}$, containing $1 \mu \mathrm{g}$ of cDNA, $100 \mathrm{ng}$ of each primer, $0.5 \mathrm{mM}$ of each dNTP, and 2.5 units of Taq DNA polymerase (Pharmacia Biotech). Amplification conditions were as follows: an initial denaturation at $94^{\circ} \mathrm{C}$ for $5 \mathrm{~min}$, followed by 35 cycles of denaturation at $94^{\circ} \mathrm{C}$ for $30 \mathrm{~s}$; annealing at $62^{\circ} \mathrm{C}$ for 1 min; and extension at $72^{\circ} \mathrm{C}$ for $2 \mathrm{~min}$, followed by a final extension for $10 \mathrm{~min}$. In the control, the muscle form, but not the brain and Purkinje-cell forms, of dystrophin transcripts was detected. In contrast to the control, the muscle form was undetectable in patient 1 , whereas the brain and Purkinje-cell forms were highly expressed (fig. 2). The brain and Purkinje-cell forms were coexpressed with the muscle form, in the other two BMD patients (patients 2 and 3; fig. 2). The level of upregulation of the brain and Purkinje-cell forms was much higher in patient 1 as compared with that in patients 2 and 3.

We first confirmed that the transcription of the brain and Purkinje-cell forms was significantly up-regulated in BMD patients with typical skeletal muscle involvement. It is likely that the promoters of the other forms, as well as the muscle promoter, are activated compensatively in these patients. These promoters probably respond to reduced expression of dystrophin, but the extent of activation of the brain and Purkinje-cell promoters may vary between different patients; the patients may differ in age, duration of disease, and degree of daily activity. Our data suggest that up-regulation of the brain and Purkinje-cell forms of dystrophin tran-

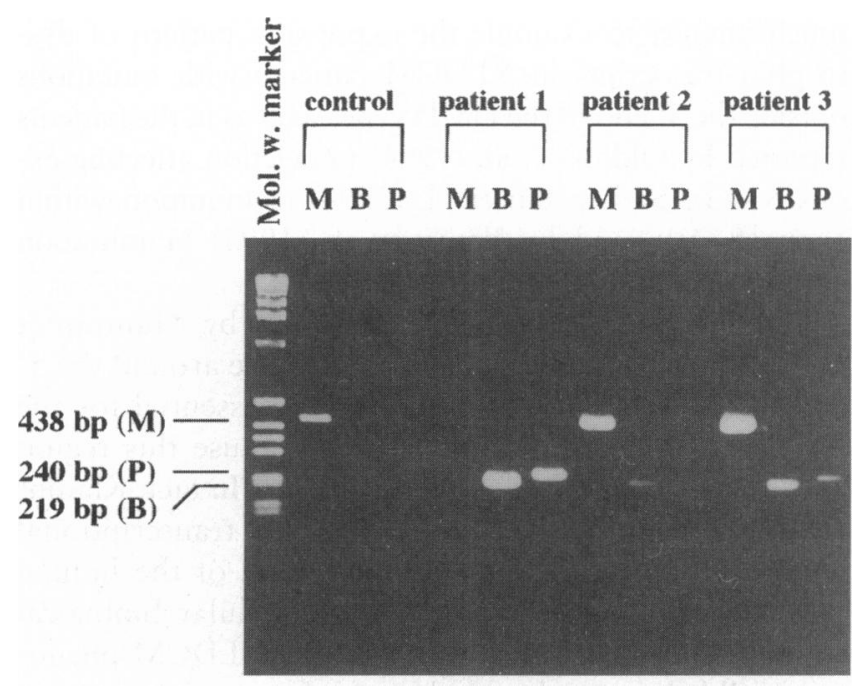

Figure 2 Expression pattern of dystrophin transcripts. RT-PCR amplification of the muscle (lanes $\mathrm{M}$ ), brain (lanes B), and Purkinjecell (lanes P) forms of dystrophin transcripts. The fragments with a size of $438 \mathrm{bp}, 219 \mathrm{bp}$, and $240 \mathrm{bp}$ correspond to the amplified muscle, brain, and Purkinje-cell forms, respectively, of dystrophin transcripts. In the control, the muscle form was detected, but the brain and Purkinje-cell forms were not detected. In contrast to the control, the muscle form was undetectable in patient 1 , whereas the brain and Purkinje-cell forms were highly expressed. In the other two BMD patients (patients 2 and 3) with hot-spot deletions (of exons 45-47 and of exons 45-48, respectively), the brain and Purkinje-cell forms, as well as the muscle form, were detected. The PCR products were separated on $2.5 \%$ agarose gels and were stained with ethidium bromide.

scripts in the skeletal muscle itself is not unique to the XLDCM phenotype. We also speculate that the stability and function of the brain and Purkinje-cell isoforms should be critical to maintenance of the cytoskeletal organization of the skeletal muscle and to protection from progressive degeneration of the muscles. In the case of so-called hot-spot mutations, such as those in patients 2 and 3, the brain and Purkinje-cell isoforms would be as unstable and ineffective as the muscle isoform, because they differ only in the $\mathrm{N}$-terminal portion encoded by the isoform-specific first exon.

We also found that the expression pattern of dystrophin transcripts in patient 1 was comparable to that of the XLDCM patients reported by Muntoni et al. (1995) and by Milasin et al. (1996). This strongly suggests that an inactivation of the muscle promoter, in combination with an activation of the brain and Purkinje-cell promoters, is characteristic to dystrophinopathy with selective cardiac involvement caused by mutations in the $5^{\prime}$ end of the DMD gene. The transcription driven by the muscle promoter may be damaged selectively by this type of mutation, whereas it cannot be disturbed by hot-spot mutations, as seen in patients 2 and 3. To further elucidate the molecular biological basis of the XLDCM phenotype, it will be of 
much interest to examine the expression pattern of dystrophin transcripts in XLDCM patients with mutations outside the $5^{\prime}$ end of the DMD gene, such as in the patients reported by Oldfors et al. (1994) (a deletion affecting exons 6-13), by Towbin et al. (1994) (a mutation within exons 8-10), and by Franz et al. (1995) (a mutation around exons 27-30).

Our results, together with the report by Muntoni et al. (1995), also indicate that the sequence around the 5' end of the first muscle intron may be essential for the functions of the muscle promoter, because this region consistently is involved in these patients. In fact, Klamut et al. (1996) recently have identified a transcriptional enhancer within the first muscle intron of the human DMD gene. Further molecular and cellular biological studies on dystrophinopathy with the XLDCM phenotype will help us understand the functions of dystrophin promoters in the skeletal and cardiac muscles.

In summary, we showed up-regulation of the brain and Purkinje-cell forms of dystrophin transcripts not only in an atypical BMD patient (patient 1) with the XLDCM phenotype, but also in typical BMD patients (patients 2 and 3). We think that the other isoforms of dystrophin can modulate the clinical features and the course of dystrophinopathy, especially with regard to the XLDCM phenotype.

\section{AKINORI NAKamura, ${ }^{1}$ SHU-ICHI IKEDA, ${ }^{1}$ MASAHIDE YAZAKI, ' KUNIHIRO YOSHIDA, Osamu Kobayashi, ${ }^{2}$ Nobuo Yanagisawa, ${ }^{1}$ AND SHIN'ICHI TAKEDA ${ }^{2}$ ${ }^{2}$ National Institute of Neuroscience, National Center}

'Department of Medicine (Neurology), Shinshu University School of Medicine, Matsumoto; and of Neurology and Psychiatry, Tokyo

\section{Acknowledgments}

This work was supported by the Research Grant for Nervous and Mental Disorders (8A-2) from the Ministry of Health and Welfare, Japan.

\section{References}

Berko BA, Swift M (1987) X-linked dilated cardiomyopathy. N Engl J Med 316:1186-1191

Franz WM, Cremer M, Herrmann R, Grünig E, Fogel W, Scheffold T, Goebel HH, et al. (1995) X-linked dilated cardiomyopathy: novel mutation of the dystrophin gene. Ann N Y Acad Sci 752:470-491

Klamut HJ, Bosnoyan-Collins LO, Worton RG, Ray PN, Davis HL (1996) Identification of a transcriptional enhancer within muscle intron 1 of the human dystrophin gene. Hum Mol Genet 5:1599-1606

Milasin J, Muntoni F, Severini GM, Bartoloni L, Vatta M, Krajinovic M, Mateddu A, et al (1996) A point mutation in the 5' splice site of the dystrophin gene first intron responsible for X-linked dilated cardiomyopathy. Hum Mol Genet $5: 73-79$

Muntoni F, Cau M, Ganau A, Congiu R, Arvedi G, Mateddu A, Marrosu MG, et al (1993) Deletion of the dystrophin muscle-promoter region associated with X-linked dilated cardiomyopathy. N Engl J Med 329:921-925

Muntoni F, Melis MA, Ganau A, Dubowitz V (1995) Transcription of the dystrophin gene in normal tissues and in skeletal muscle of a family with X-linked dilated cardiomyopathy. Am J Hum Genet 56:151-157

Oldfors A, Eriksson BO, Kyllerman M, Martinsson T, Wahlström J (1994) Dilated cardiomyopathy and the dystrophin gene: an illustrated review. Br Heart J 72:344-348

Sakuraba H, Ishii K, Shimmoto M, Yamada H, Suzuki Y (1991) A screening for dystrophin gene deletions in Japanese patients with Duchenne/Becker muscular dystrophy by the multiplex polymerase chain reaction. Brain Dev 13:339342

Towbin JA, Hejtmancik JF, Brink P, Gelb B, Zhu XM, Chamberlain JS, McCabe ERB, et al. (1993) X-linked dilated cardiomyopathy: molecular genetic evidence of linkage to the Duchenne muscular dystrophy (dystrophin) gene at the Xp21 locus. Circulation 87:1854-1865

Towbin JA, Ortiz-Lopez R, Bulman D, Ray PN, Franz W-M, Katus H, Swift M, et al. (1994) A novel cardio-specific dystrophin mutation as a cause of X-linked dilated cardiomyopathy (XLCM). Pediatr Res Suppl 37:36A

Yoshida K, Ikeda S, Nakamura A, Kagoshima M, Takeda S, Shoji S, Yanagisawa N (1993) Molecular analysis of the Duchenne muscular dystrophy gene in patients with Becker muscular dystrophy presenting with dilated cardiomyopathy. Muscle Nerve 16:1161-1166

Address for correspondence and reprints: Dr. Kunihiro Yoshida, Department of Medicine (Neurology), Shinshu University School of Medicine, 3-1-1 Asahi, Matsumoto 390, Japan. E-mail: naokosy@gipac.shinshu-u.ac.jp (C) 1997 by The American Society of Human Genetics. All rights reserved. 0002-9297/97/6006-0039\$02.00

Am. J. Hum. Genet. 60:1558-1562, 1997

\section{Bilateral Retinoblastoma in a Male Patient with an $X ; 13$ Translocation: Evidence for Silencing of the RB1 Gene by the Spreading of $X$ Inactivation}

\section{To the Editor:}

We describe a male patient who has an X;13 translocation and bilateral retinoblastoma. DNA replication and methylation studies for this patient suggested that $\mathrm{X}$ inactivation had spread to chromosome 13 and had produced functional monosomy for genes on proximal 13q. Inactivation of both alleles of the RB1 gene in 13q14 comprises the two rate-limiting steps in the formation of retinoblastoma (Knudson 1975; Cavenee et al. 1983). In hereditary retinoblastoma, one allele is inactivated or 